American Journal of Environmental Sciences 4 (2): 145-150, 2008

ISSN 1553-345X

(C) 2008 Science Publications

\title{
A screen for Benzo(a)pyrene in Fish Samples From Crude Oil Polluted Environments
}

\author{
${ }^{1}$ Chimezie Anyakora, ${ }^{2}$ Mohsen Arbabi and ${ }^{1}$ Herbert Coker \\ ${ }^{1}$ Department of Pharmaceutical Chemistry, University of Lagos. NIGERIA \\ ${ }^{2}$ Department of Environmental Health Engineering, School of Health, Shahrekord \\ University of Medical Sciences, IRAN
}

\begin{abstract}
Several studies have shown that exposure to Benzo(a)pyrene increases the risk of cancer. In this study several fish samples from Niger the Delta region of Nigeria were screened for the presence of Benzo(a)pyrene. The study was carried out using Gas chromatograph coupled to a mass spectrometry detector. Benzo(a)pyrenes in the samples were identified through both retention time match with authentic standards and simultaneous maximization of several major ions from GC/MS data. Perylene- ${ }_{\mathrm{d} 12}$ was used as the internal standard for quantitation. Concentration of benzo(a)pyrene in the samples ranged from 1.47 to $10.53 \mu \mathrm{g} / \mathrm{kg}$ which is more than WHO recommended maximum allowable concentration. Therefore this study concludes that the population is at an elevated risk of cancer of occurrence.
\end{abstract}

Keywords: cancer, delta region of Nigeria, chromatograph

\section{INTRODUCTION}

Benzo(a)pyrene (BaP) (Fig. 1) is a five-ring polynuclear aromatic hydrocarbon $(\mathrm{PAH})$, belonging to the alternant class of PAHs ${ }^{[1]}$. It is known to be a ubiquitous environmental carcinogen. BaP has evoked much interest due to its carcinogenic properties. A variety of tests have shown $\mathrm{BaP}$ to be genetoxic. It has produced stomach tumor, mammary gland tumor, lung and respiratory tumors, hepatic tumors in laboratory animals $^{[2]}$. Human exposure to $\mathrm{BaP}$ occurs through several routes namely the skin, the gastrointestinal tract and the pulmonary $\operatorname{tract}^{[3]}$. It is generated by incomplete combustion of organic materials arising in part from natural combustion such as forest fires and volcanic eruption $^{[4-6]}$. Anthropogenic sources such as industrial production, transportation and waste incineration generate significant amount of this compound and other $\mathrm{PAHs}^{[7]}$. Petroleum production, import and export of petroleum product also contribute a lot to the extent of $\mathrm{BaP}$ contamination especially in marine samples. Other sources include crude oil contamination of ground water and fishes, tobacco smoke, exhaust fumes and combustion of all forms of fossil fuel.

The carcinogenesis of $\mathrm{BaP}$ is basically a result of its ability to bind to the DNA thereby causing a series of disruptive effects that end up in tumor initiation. The aromatic hydrocarbon receptor plays a very important role in this. Benzo(a)pyrene induced carcinogenesis involves 3 stages. First is the enzymatic activation of the compound into metabolites ${ }^{[8]}$. The second stage in the carcinogenesis of benzo(a)pyrene is the covalent bonding of anti-BPDE to DNA to form BPDE-DNA adduct ${ }^{[9]}$. The last stage is the induction of mutations that serve to initiate the transformation process as a result of BPDE-DNA adducts ${ }^{[10]}$.

PAHs never occur as individual compounds in the environment ${ }^{[11]}$, they occur as a mixture of many other polynuclear aromatic hydrocarbons. Several findings have revealed that weakly or non carcinogenic PAHs present in a mixture can modify the carcinogenic activities of a given polynuclear aromatic hydrocarbons such as Benzo(a)pyrene in rodent ${ }^{[12-15]}$.

Benzo(a)pyrene being fat soluble, tend to bioaccumulate in marine organisms ${ }^{[16]}$ in contaminated coastal environments, the Niger Delta being one of such environments. The Niger Delta region contains both fresh inland waters and a highly urbanized brackish ecosystem impacted by municipal and industrial activities, and more significantly by the extensive petroleum production activities in the area. A major concern is that fish from this region represent a significant component of the diet of a large percentage of the population, and this could present a number of

Corresponding Author: Chimezie Anyakora, Department of Pharmaceutical Chemistry, University of Lagos NIGERIA 
human health problems. In this study, seventeen fish samples from four different species, namely Parachanna Obscura, Pseudolithus Elongatus, Lizza Dumerillii and Clarais Gariepinnus, were screened for the presence benzo(a)pyrene using GC/MS. Parachanna Obscura and Clarais Gariepinnus are fresh water fishes while Pseudolithus Elongatus and Lizza Dumerillii are from brackish ecosystem. This study targets these four species of fish because of their wide spread consumption in the Niger Delta and environs. The study revealed a relatively high degree of benzo(a)pyrene accumulation in all the fish samples.<smiles>c1ccc2c(c1)cc1ccc3cccc4ccc2c1c34</smiles>

Fig 1: Chemical Structure of Benzo(a)pyrene.

\section{EXPERINMENTAL}

Collection of samples: The fish samples were collected directly from their natural ecosystem. Two species Pseudolithus Elongatus and Lizza Dumerillii were sampled from brackish ecosystem, while Clarais Gariepinnus and Parachanna Obscura were sampled from fresh water ecosystem. The Nigerian Institute of Oceanography and Marine Research Lagos identified the fish species.

Reagents: All chemicals and reagents were of analytical grade and of highest purity possible. LCgrade dichloromethane used for extractions was obtained from Fischer Scientific, Silica gel used to clean up the extracts was supplied by $\mathrm{BDH}$ Laboratories. A PAH standard mixture (NIST, Baltimore, MD) containing naphthalene, acenaphthylene, acenaphthene, fluorene, phenanthrene, anthracene, fluoranthene, pyrene, benz[a]anthracene, chrysene, benzo[b]flouranthene, benzo[k]flouranthene, benzo[a]pyrene, benzi[ghi]perylene dibenzo[a,h]anthracene and indeno[1,2,3-cd]pyrene was used in this study. A mixture containing four isotopically labeled PAHs (ChemService, Westchester, PA) namely acenaphthalene- ${ }_{\mathrm{d} 10}$, chrysene- ${ }_{\mathrm{d} 12}$, phenanthrene- d10 $_{10}$ and perylene- $\mathrm{d}_{12}$ was used as an internal standard.

Soxhlet Extraction: $10 \mathrm{~g}$ of fresh fish fillet was homogenized in a mortar with about $10 \mathrm{~g}$ of $\mathrm{Na}_{2} \mathrm{SO}_{4}{ }^{[17]}$ until a completely dry homogenate was obtained. The Soxhlet apparatus consisted of a $250 \mathrm{~mL}$ round bottom flask, condenser and extractor tube, seated in a temperature-controlled heating mantle. A Fischer brand rotovap was used for evaporating the extracts to the desired concentration. The homogenate was carefully transferred into the extraction thimble and placed in the extraction chamber of a Soxhlet extraction unit. Soxhlet extractions were carried out using a modified form of the EPA 3540 method $^{[18]}$ using $150 \mathrm{~mL}$ dichloromethane for 16 hours. The extract was concentrated in a rotavap.

Post-Extraction Cleanup: The extract was concentrated to $1 \mathrm{~mL}$ and loaded onto a silica gel column. The silica gel column was prepared by loading an activated silica gel onto a chromatographic column (1 cm internal diameter) to about $5 \mathrm{~cm}$. An additional 1 $\mathrm{cm}$ of anhydrous $\mathrm{Na}_{2} \mathrm{SO}_{4}$ was added to the column. This was conditioned with methylene chloride. $1 \mathrm{~mL}$ of concentrated extract was loaded and eluted with $10 \mathrm{~mL}$ of methylene chloride ${ }^{[19]}$. This procedure was able to remove the very polar lipids off the extract. The lipids, being very polar, were adsorbed at the top of the column. Prior to analysis $0.5 \mu \mathrm{g}$ of four internal standards were added to each of the sample extract and the volume reduced to $1 \mathrm{~mL}$.

Analysis: The GC/MS system used for the analyses consisted of a Finnigan Magnum instrument equipped with a CTC A200S autosampler, a 30 m, 0.25 ID DB$5 \mathrm{~ms}$ fused silica capillary column ( $\mathrm{J} \& \mathrm{~W}$ Scientific, Folson CA), and the Finnigan Magnum data system. Helium was used as the carrier gas and the column head pressure was maintained at $10 \mathrm{psi}$ to give an approximate flow rate of $1 \mathrm{~mL} / \mathrm{min}$. The injector and transfer line were maintained at $290^{\circ} \mathrm{C}$ and $250 \mathrm{C}$ respectively. All injection volumes were $1 \mu \mathrm{L}$ in the splitless mode. The column temperature was initially held at $70^{\circ} \mathrm{C}$ for 4 minutes, ramped to $300^{\circ} \mathrm{C}$ at a rate of $10^{\circ} \mathrm{C} / \mathrm{min}$, then held at $300^{\circ} \mathrm{C}$ for 10 minutes [20]. The mass spectrometer was used in electron ionization mode and all spectra were acquired using a mass range of m/z $50-400$ and automatic gain control (AGC).

\section{RESULTS AND DISCUSSION}

Chromatographic study: GC conditions were set using conditions similar to those in related studies [20]. Even though the target compound is $\mathrm{BaP}$, in this study GC conditions and standards for sixteen priority PAHs (which $\mathrm{BaP}$ is part of) are employed. The column 
temperature program gave baseline separation of the target compounds in a reasonable amount of time, with BaP eluting after 27.18 minutes (Fig. 2).

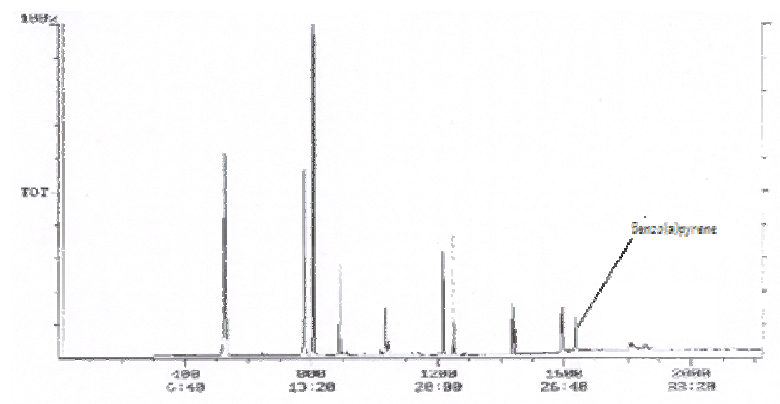

Fig. 2: Total ion chromatogram for the standard used in the study. $\mathrm{BaP}$ is highlighted. The chromatographic conditions are as described above. The retention time of $\mathrm{BaP}$ is 27.18 mins.

To evaluate the extraction efficiency of $\mathrm{BaP}$ from fish matrix, recovery studies were carried out using

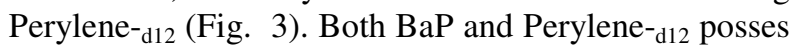
five aromatic rings and hence perylene- $\mathrm{d}_{12}$ is a good surrogate for $\mathrm{BaP}$. The percent recovery of $118 \%$ was obtained, and this demonstrates no significant losses of analytes during the sample workup process. The surrogate percent recovery was calculated using the equation:

$$
\% R=\frac{Q_{d}}{Q_{a}} \times 100
$$

Where $\mathrm{Q}_{\mathrm{d}}$ is the quantity determined by analysis; and $\mathrm{Q}_{\mathrm{a}}$ is the quantity added. For surrogate percent recovery to be acceptable it must fall between 60 and $120 \%{ }^{[21]}$<smiles>[2H]C1=C([2H])C2=C([2H])C([2H])=C([2H])c3c([2H])c([2H])c([2H])c4c3C2C(=C1[2H])C1=C([2H])C([2H])=C([2H])c2c([2H])c([2H])c([2H])c1c2-4</smiles>

Fig. 3: Chemical structure of Perylene- ${ }_{\mathrm{d} 12}$

Several dilutions of the standard were analyzed to determine the limit of detection (LOD), limit of quantitation (LOQ), limit of linearity (LOL), relative standard deviation (RSD) and regression coefficient $\left(\mathrm{r}^{2}\right)$. The LOD was determined by the signal to noise ratio of $3: 1$. The LOQ was determined by the signal to noise ratio of 10:1. The LOL was determined from the plot of the concentration versus response. The RSD was determined by triplicate of each analysis. The $r^{2}$ was determined for the compound using Microsoft Excel formula software. Fig. 4 shows the calibration curve for $\mathrm{BaP}$ obtained using a series of varying concentrations of $\mathrm{BaP}$. The curve is linear with correlation coefficients from the linear regression of 0.995. Relative standard deviation from replicate analyses of the same standard $(\mathrm{n}=3)$ was $2.11 \%$ (Table 1). Limits of detection and quantitation (LODs and LOQs) were $0.15 \mu \mathrm{g} / \mathrm{mL}$ and $0.5 \mu \mathrm{g} / \mathrm{mL}$ respectively. $\mathrm{BaP}$ in the samples was identified by a combination of a retention time match and mass spectral match against the calibration standards. Quantitation was performed by the method of internal standardization using Perylene- $_{\mathrm{d} 12}$ as the internal standard based on the ratio of the peak height of the $\mathrm{BaP}$ ion to that of the internal standard. Fig. 5 shows the total ion chromatogram of a representative fish extract analyzed in this study.

Table 1: Analytical Characteristics of the compound

\begin{tabular}{ll}
\hline Compound name & Benzo(a)pyrene \\
\hline Retention time & 27.18 minutes \\
Linearity range & $0.123-1.228 \mu \mathrm{g} / \mathrm{ml}$ \\
Regression coefficient & 0.995 \\
Relative Standard Deviation & $2.11 \%$ \\
Limit of Detection & $0.15 \mu \mathrm{g} / \mathrm{ml}$ \\
Limit of Quantitation & $0.50 \mu \mathrm{g} / \mathrm{ml}$ \\
Important $\mathrm{m} / \mathrm{z}$ & $252,225,161,126,74$ \\
Molecular Formular & $\mathrm{C}_{20} \mathrm{H}_{12}$ \\
Molecular weight & 252 \\
\hline
\end{tabular}

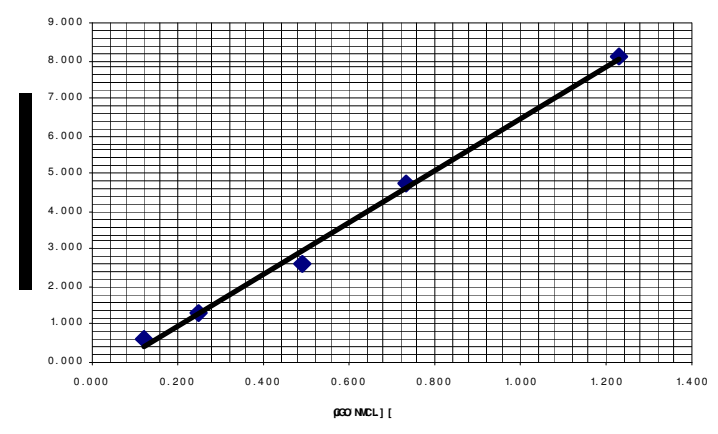

Fig. 4: Calibration curve for $\mathrm{BaP}$ 


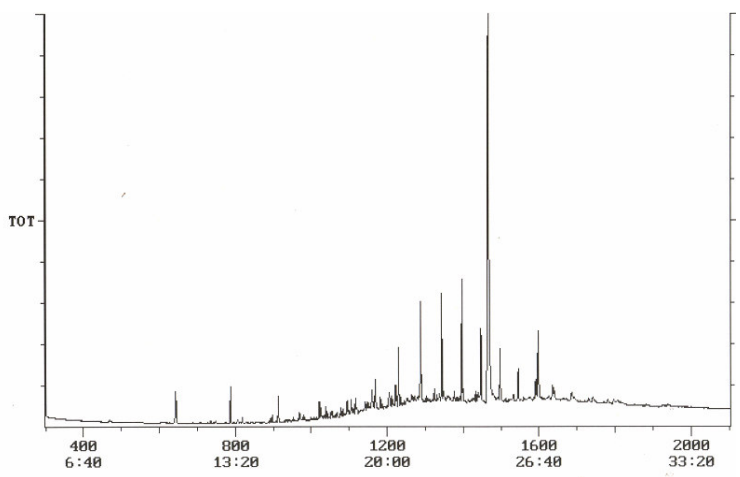

Fig. 5: Total ion chromatogram of a representative fish extract analyzed in this study. Chromatographic conditions are as described above

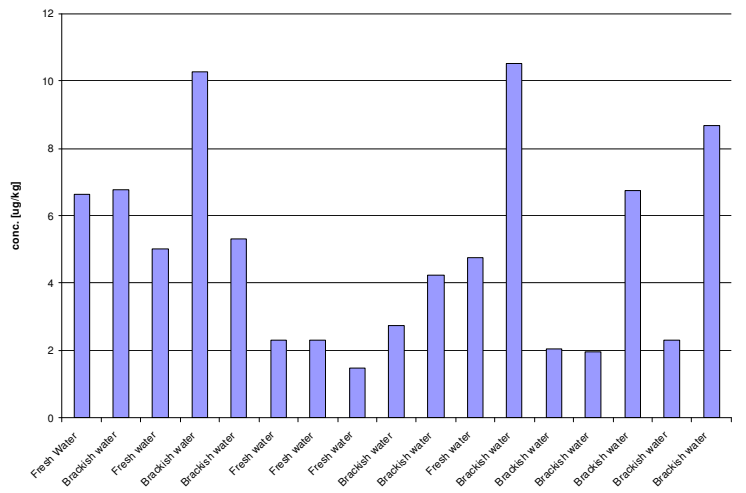

Fig. 6: BaP distribution in fish of different ecosystems

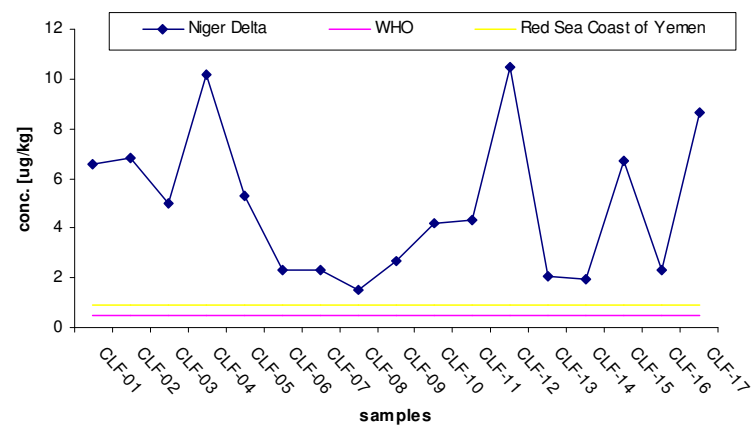

Fig. 7: $\mathrm{BaP}$ profile in the studied fish samples compared with WHO benchmark and results Red Sea Coast of Yemen.

Benzo(a)pyrene Concentration in the Samples: All 17 samples contain $\mathrm{BaP}$ in significant amount indicating a high level of contamination. The concentration levels ranged from $1.5 \mu \mathrm{g} / \mathrm{kg}$ to 10.2 $\mu \mathrm{g} / \mathrm{kg}$. Table 2 shows the concentration levels of $\mathrm{BaP}$ in the studied samples. The BaP concentration did not show any particular trend in different species of fish. Both fresh water and brackish water species have concentration close to each other with the exception of a few deviation (Fig. 6). Therefore we can say that the level of $\mathrm{BaP}$ accumulation is a function of the level of contamination in a given environment. Fig. 6 illustrates this better.

Table 2: $\mathrm{BaP}$ concentrations in different fish samples

\begin{tabular}{lll}
\hline Fish sample & Type of Sample & $\begin{array}{l}\text { BaP conc. } \\
\text { in ug/kg }\end{array}$ \\
\hline Sample 1 & Fresh Water & 6.64 \\
Sample 2 & Brackish water & 6.78 \\
Sample 3 & Fresh water & 5.01 \\
Sample 4 & Brackish water & 10.27 \\
Sample 5 & Brackish water & 5.32 \\
Sample 6 & Fresh water & 2.32 \\
Sample 7 & Fresh water & 2.3 \\
Sample 8 & Fresh water & 1.47 \\
Sample 9 & Brackish water & 2.74 \\
Sample 10 & Brackish water & 4.24 \\
Sample 11 & Fresh water & 4.77 \\
Sample 12 & Brackish water & 10.53 \\
Sample 13 & Brackish water & 2.06 \\
Sample 14 & Brackish water & 1.98 \\
Sample 15 & Brackish water & 6.74 \\
Sample 16 & Brackish water & 2.3 \\
Sample 17 & Brackish water & 8.67 \\
\hline
\end{tabular}

Fig. 7 shows the profile of benzo(a)pyrene in the studied fish samples. The profile is compared with the WHO recommended background concentration of benzo(a)pyrene of $0.5 \mu \mathrm{g} / \mathrm{kg}$ in food samples ${ }^{[22]}$ and the result obtained from Red Sea Coast of Yemen ${ }^{[23]}$. The Fig. clearly shows that the studied samples contain $\mathrm{BaP}$ in concentrations higher than the WHO recommended minimum and when compared with another environment in this case Red Sea coast of Yemen, with average concentration of $0.9 \mu \mathrm{g} / \mathrm{kg}$, it shows that the level of contamination is much more in this environment too.

$\mathrm{BaP}$ like many other PAHs bioaccumulates in fish tissues because of their lipophilic nature ${ }^{[16]}$. Based on estimated fish consumption by the population of 40 $\mathrm{g} /$ day, the daily intake of carcinogenic $\mathrm{BaP}$ can be calculated as:

$\left[40 \mathrm{~g} /\right.$ person/day x $\left.\left\{\mathrm{C}_{\mathrm{BaP}}\right\}_{\mathrm{a}} \mu \mathrm{g} / \mathrm{kg}\right] / 1000 \mathrm{~g} / \mathrm{kg}$ 
where $\mathrm{C}_{\mathrm{BaP}}$ is the concentration of $\mathrm{BaP}$ in an individual fish sample studied. $\left\{\mathrm{C}_{\mathrm{BaP}}\right\}_{\mathrm{a}}$ is the mean of $\mathrm{BaP}$ in the sample population. From table 2 the mean concentration of $\mathrm{BaP}$ for the samples is $4.95 \mu \mathrm{g} / \mathrm{kg}$, therefore the daily consumption of $\mathrm{BaP}$ can be given as:

[40 g/person/day x 4.95 $\mu \mathrm{g} / \mathrm{kg}] / 1000 \mathrm{~g} / \mathrm{kg}=0.198 \mu \mathrm{g} /$ person/day

Fish is a major source of PAH exposure to man [24]. Its contribution to food is influenced by method of preparation [25]. Smoking and charboiling are additional sources of carcinogenic PAHs [26]. Other food sources such as vegetable, fruits and cereal from the area are bound to be contaminated, hence adding to the daily intake of carcinogenic PAHs by the population. This implies that this population is exposed to high level of this toxicant which has an adverse health implication.

\section{CONCLUSION}

The continued and long exposure of man to $\mathrm{BaP}$ may significantly influence the high rate of prostrate hyperplasia in men residing in these areas, as well as other toxicological and carcinogenic manifestations in humans.

\section{REFERENCES}

1. Harvey R.G., 1997. Polycyclic Aromatic Hydrocarbons, New York, Wiley-VCH.

2. ATSDR, 1995. Toxicological profile for polycyclic aromatic hydrocarbons (PAH). Atlanta, GA, US Department of Health and Human Services, Public health service, agency for toxic substances and disease registry.

3. WHO, 1998. Polynuclear Aromatic Hydrocarbons. In: Guidelines for Drinking-water Quality, 2nd ed. Vol. 2. Health Criteria and other Supporting Information. Geneva, World Health Organization, pp. 123 - 152.

4. Guillen M.D., P. Sopelana and M.A. Partearroyo, 2000. Polycyclic aromatic hydrocarbons in liquid smoke flavorings obtained from different types of wood. Effect of storage in polyethylene flasks on their concentrations. J. Agric. Food Chem., 48: 5083 - 5087.

5. Grova N, C. Feidt, C. Crepineau, C. Laurent, P.E. Lafargue, A. Hachimi and G. Rychen, 2002. Detection of Polycyclic Aromatic Hydrocarbon level in Milk Collected Near Potential Contamination Sources. J. Agric. Food Chem. 50: 4640 - 4642.
6. Anyakora, C., A. Ogbeche, H. Coker, G. Ukpo and C. Ogah, 2004. A screen for Benzo(a)pyrene, a carcinogen, in the water samples from the Niger Delta Using GC-MS. Nigerian Quarterly Journal of Hospital Medicine, 14: 288 - 295.

7. Yang, H.H., W.J. Lee, S.J. Chen and S.O. Lai, 1998. PAH emission from various industrial stacks. J. Hazard. Mater., 60: 159 - 174.

8. Martson C.P., C. Pareira, J. Ferguson, K. Fischer, H. Olaf, W. Dashwood and W.M. Baird, 2001. Effect of complex environmental mixture from coal tar containing polycyclic aromatic hydrocarbons (PAH) on tumor initiation, PAHDNA binding and metabolic activation of carcinogenic PAH in mouse epidermis. Carcinogenesis, 22(7): 1077 - 1086.

9. Thakker D.R., H. Yagi, W. Levin, A.W. Wood, A.H. Conny and D.M. Jerina, 1985. Polynuclear aromatic hydrocarbons: metabolic activation ultimate carcinogens. In: Bioactivation of foreign compounds (ed. W.M. Anders) pp. 177 - 242 Academic Press, New York.

10. CEFAS, 2000. Biomarkers for PAH exposure in fish and their application in marine monitoring. Centre for environment, fisheries and aquaculture sciecnces.

11. Mottier P., V. Parisod and R.J. Turesky, 2000. Quantitative Determination of polycyclic aromatic hydrocarbons in barbecued meat sausages by gas chromatography coupled to mass spectrometry. J. Agric. Food Chem., 48: 1160 - 1166.

12. Van Duuren B.L. and M.M. Goldschmidt, 1976. Carcinogenic and tumour promoting agents in tobacco-carcinogenesis. J. Natl Cancer Inst. 56: 1237 - 1242.

13. DiGiovanni J., J. Rymer, T.J. Slaga and R.K. Boutwell, 1982. Anticarcinogenic and carcinogenic effect of benzo(a)pyrene and dibenz(a,c)anthracene on skin tumor initiation by polycyclic hydrocarbons. Carcinogenesis, 3: $371-375$.

14. Slaga T.J. and J. DiGiovanni, 1984. Inhibition of chemical carcinogenesis. ACS Monogr. 102:1279 1321.

15. Nesnow S., 1990. Mouse skin tumour and human lung cancer: Relationship with complex environmental emissions. In: Complex mixtures and cancer risk (eds. H. Vainio, M. Sorsa and A.J. Mcmichael), pp. $44-54$, IARC Scientific Publications No. 104, IARC, Lyon.

16. Atlas R.M., 1991. Microbial hydrocarbon degradation: Bioremediation of oil spills. Biotechnol. 52: 149-156. 
17. Wang G., A.S. Lee, M. Lewis, B. Kamath and R.K. Archer, 1999. Accelerated solvent extraction and gas chromatography/mass spectrometry for determination of polycyclic aromatic hydrocarbons in smoked food samples. J Agric Food Chem.47:3 1062-1066.

18. US EPA, 1994. Soxhlet Extraction - Method 3540.

19. Anyakora C., A. Ogbeche, P. Palmer and H. Coker, 2005. Determination of Polynuclear aromatic hydrocarbons in marine samples from Siokolo Fishing settlement. Journal of Chromatography A, 1073: 323 - 330 .

20. Anyakora C., A. Ogbeche, P. Palmer, H. Coker, G. Ukpo, and C. Ogah, 2005. GC/MS analysis of polynuclear aromatic hydrocarbons in sediment samples from the Niger Delta region. Chemosphere, 60: 990 - 997.

21. US EPA, 1999. Method TO-13A, Compendium of Methods for Toxic Air Pollutants.
22. WHO, 1998. Polynuclear aromatic hydrocarbons. In: Guidelines for drinking-water quality, 2nd ed. Vol. 2. Health criteria and other supporting information. Geneva, World Health Organization, pp. $123-152$.

23. DouAbul A.A-Z, H.M.A. Heba and K. H. Fareed, 1997. Polynuclear aromatic hydrocarbons (PAHs) in fish from the Red Sea Coast of Yemem. Hydrobiologia. 352: $251-262$.

24. Santodonato J., 1981. Polycyclic organic matter. J Environ Pathol Toxicol., 5:1-364.

25. Simko P., 2002. Determination of Polycyclic Aromatic Hydrocarbons in Smoked Meat Products and Smoke Flavouring Food Additives. $J$. Chromatogr. B. 770: 3-18

26. Menzie C.A., B.B. Potocki and J. Santodonato, 1992. Exposure to carcinogenic PAH in the environment. Environ. Sci. Technol. 26: 12781284. 